\title{
Economic advantages of applying model predictive control to distributed energy resources: The case of micro-CHP systems*
}

\author{
M. Houwing, R.R. Negenborn, and B. De Schutter
}

If you want to cite this report, please use the following reference instead:

M. Houwing, R.R. Negenborn, and B. De Schutter, "Economic advantages of applying model predictive control to distributed energy resources: The case of micro-CHP systems," Proceedings of the 16th Mediterranean Conference on Control and Automation (MED'08), Ajaccio, France, pp. 1550-1555, June 2008.

Delft Center for Systems and Control

Delft University of Technology

Mekelweg 2, 2628 CD Delft

The Netherlands

phone: +31-15-278.24.73 (secretary)

URL: https: / / www.dcsc.tudelft.nl

*This report can also be downloaded viahttps://pub. deschutter.info/abs/08_009.html 


\title{
Economic Advantages of Applying Model Predictive Control to Distributed Energy Resources: The Case of Micro-CHP Systems
}

\author{
Michiel Houwing, Rudy R. Negenborn, and Bart De Schutter
}

\begin{abstract}
The increasing presence of distributed energy resources, information, and intelligence in the electricity infrastructure increases the possibilities for larger economic efficiency of power systems. This work shows the possible cost advantages of applying a model predictive control (MPC) strategy to residential energy systems. MPC can take future information on energy demand and prices into account and might lead to lower energy costs for end consumers. The main objective in this paper is to illustrate the potential for operational cost savings when adopting MPC in the local control of residential energy systems, thereby mainly focusing on micro-combined heat and power (micro-CHP) systems. We conclude that the pricing regime of household energy has a large influence on potential cost savings.
\end{abstract}

Keywords: Demand response; Distributed energy resources; Energy efficiency; Micro-combined heat and power; Model predictive control; Smart power systems.

\section{Introduction}

\subsection{Distributed energy resources}

Distributed energy resources (DERs) are expected to play a significant role in the future electricity sup-

Work supported by the BSIK project "Next Generation Infrastructures (NGI)", the project "Multi-agent control of largescale hybrid systems" (DWV.6188) of the Dutch Technology Foundation STW, the European Network of Excellence "HYbrid CONtrol: Taming Heterogeneity and Complexity of Networked Embedded Systems (HYCON)", and the Delft Research Center Next Generation Infrastructures.

M. Houwing is with the Faculty of Technology, Policy and Management of the Delft University of Technology, Jaffalaan 5, 2628 BX Delft, The Netherlands. (Corresponding author; email: m.houwing@tudelft.nl; phone: +31-152781340; fax: +31152783422).

R.R. Negenborn and B. De Schutter are with the Delft Center for Systems and Control of Delft University of Technology, Mekelweg 2, 2628 CD Delft, The Netherlands. B. De Schutter is also with the Marine and Transport Technology department of the Delft University of Technology. (E-mail: r.r.negenborn@tudelft.nl, b@deschutter.info). ply, see e.g., [1,2]. The concept of DERs comprises distributed electricity generation, distributed energy storage, and responsive energy loads. DERs can play a crucial role in supporting key policy objectives such as electricity market liberalization, mitigating climate change, increasing the amount of electricity generated from renewable sources, and enhancing energy savings.In this paper we focus on residential or micro $(\mu)$ DERs. Households consume final energy mainly in the form of electricity and heat and the domestic sector generally accounts for a large part of a country's electricity and natural gas consumption. Specific potential for applying distributed generators at customer sites lies in utilizing electricity and heat from combined heat and power (CHP) systems. This leads to more efficient energy use and thus to cost savings and carbon emission reductions [3]. There has been significant progress toward developing $\mathrm{kW}$-scale CHP applications, so-called micro-CHP or $\mu \mathrm{CHP}$ systems. These systems can be based on a Stirling engine, an internal combustion engine, a gas turbine, or fuel cell conversion technology $[1,3]$. For example, Stirling $\mu \mathrm{CHP}$ systems are expected to pervade the Dutch market substantially in the short- to midterm [4]. In the UK, Germany, and Japan $\mu \mathrm{CHP}$ technology is also expected to play a significant role [3]. In addition, the introduction of more information and communication technology (ICT) facilitates the intelligent control of power networks and DER technologies, thereby creating 'smart' power systems. An ICT-enabled service that utilities could provide to their residential customers, e.g., is offering varying electricity tariffs. Residential energy management systems could then anticipate future price changes leading to substantial operational cost savings.

\subsection{Paper objective and organization}

This paper focuses on the intelligent control of Stirling $\mu \mathrm{CHP}$ technology and connected residential energy storage systems. Thermal and electric load shifting is hereby outside the scope of this paper. 
In previous work [5] we have already illustrated the possibility of achieving operational cost savings by controlling DERs more sophisticatedly. The current work gives more thorough insight in the possible savings due to the use of a better system model, substantially better optimization solver algorithms, and by simulating over longer time periods and with much longer prediction horizons. We also present new results on the comparison of flexible $\mu \mathrm{CHP}$ control with stringent, heat-led, control as well as on the influence of electricity storage in the controlled system. In that way we clearly show which elements of the controlled system are most responsible for the cost savings. We further also provide an overview of the incentives for the involved actors to engage in contracts providing the necessary real-time electricity tariffs for intelligent local control of DERs.

The paper is organized as follows. In Section II we describe the system under study as well as the concept of model predictive control (MPC). In Section III the economic incentives for the involved actors to apply MPC to residential DERs are explained. In Section IV the mathematical system models and control objectives are described. In Section $\mathrm{V}$ we illustrated the performance of the proposed controller through simulation studies on various, increasingly complex systems.

\section{System Description and MPC}

\subsection{System description}

The analysis in this paper mainly focuses on the system shown in Fig. 1. The household can fulfill its electricity and heat demand through several alternative means. The $\mu \mathrm{CHP}$ unit installed in the household is based on Stirling technology [3]. Such a unit consists of a Stirling engine prime mover, conversion unit 1 , and an auxiliary burner, conversion 2 , which can provide additional thermal power. The Stirling engine converts natural gas $\left(f_{1}\right)$ into electrical energy $(g)$ and heat $\left(h_{1}\right)$. The heat is supplied in the form of hot water to a central heat storage, the energy content of which is indicated by $h_{\mathrm{s}}$. The auxiliary burner also converts natural gas $\left(f_{2}\right)$ into additional heat $\left(h_{2}\right)$. Heat consumption $\left(h_{\mathrm{c}}\right)$ is taken from the heat storage. Electrical energy can be stored in a battery $\left(e_{\mathrm{s}}\right)$ (e.g., a lithium-ion battery). Electrical energy can flow to and from the battery, represented by $\left(s_{\mathrm{i}}\right)$ and $\left(s_{\mathrm{O}}\right)$, respectively. Locally generated electricity can be used directly by the household $\left(e_{\mathrm{c}}\right)$, it can be stored, or it can be sold to the supplier $\left(e_{\text {ext }}\right)$. Electricity can also be imported from the supplier $\left(i_{\text {ext }}\right)$. The supplier thus sells primary fuel $\left(f_{1}+f_{2}\right)$ as well as electricity to the household. The supplier receives exported electricity from the household and possibly pays households a certain feed-back tariff.

\subsection{Model predictive control}

To exploit the increased operational freedom in households with DER systems, we propose a decentralized controller for household energy flows. The controller uses the control technique Model Predictive Control (MPC) [6] and has the task to automatically determine which actions should be taken in order to minimize the operational costs of fulfilling residential electricity and heat requirements subject to operational constraints. There are distinct and predictable patterns in residential energy demand and energy market prices of which predictive control can take advantage. The proposed controller uses MPC to:

- take into account the decision freedom due to heat and electricity storage possibilities;

- incorporate predictions on residential electricity and heat demands and energy prices;

- incorporate models of the dynamics and constraints of installed generators and storages.

MPC is based on solving at each control step an optimization problem over a prediction horizon subject to system dynamics, an objective function, and constraints on states, actions, and outputs. At each control step the optimization yields a sequence of actions optimizing expected system behavior over the prediction horizon. The controller applies the computed actions (control inputs) to the system until the next control step, after which the procedure is repeated with new system measurements. Due to the prediction horizon an MPC controller can take benefit of knowledge that it may have about the future, such as predicted energy demand or energy prices.

\section{Economic Aspects of Applying MPC to DERs}

\subsection{Four increasingly complex system models}

To place the potential cost savings of applying MPC to the system described above in a broader perspective, we analyze four system models, each representing less advanced versions of the system of Fig. 1. 


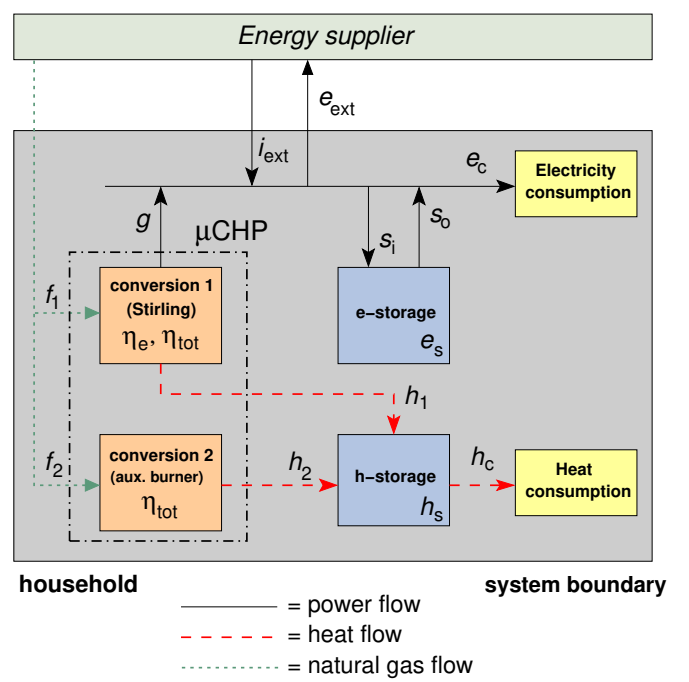

Figure 1: Conceptual overview of the system under study.

The four systems that we consider with accompanying overviews of the costs for the two actors involved in our analysis are shown in Fig. 2. The actors are the household with the locally installed and controlled DERs and an aggregator. We assume the aggregator to be an energy supply company.

The first and least advanced system consists of a household with a conventional heating system: a high-efficiency condensing boiler and a hot-water storage. The house hold imports all required electricity. The second and slightly more advanced system involves a household with a $\mu$ CHP unit that is stringently (i.e., heat-led) controlled. This control mode is explained further below in the paper. The third system includes a more flexible MPCcontrolled $\mu \mathrm{CHP}$ system, and the fourth and most advanced system in addition has a battery to store electricity. The configuration of the fourth system is the system depicted in Fig. 1.

\subsection{Operational costs in the four sys- tems}

It is now our hypothesis that each subsequent system will lead to more operational cost savings for households as well as for the aggregator. Looking at the first system, the aggregator and the household will incur operational revenues and costs over a certain period of time; the aggregator will incur a net revenue (profit) and the household a net cost.

The second system involves a household with a stringently-controlled $\mu$ CHP system. Deploying the $\mu \mathrm{CHP}$ will lead to lower $\mathrm{CO}_{2}$ emissions $[3,7]$ and this alone might be enough reason for some households to invest in these systems. Another reason may be the increased reliability of power supply. It is plausible, however, that a household will only invest in a $\mu \mathrm{CHP}$ system if the additional investment with respect to a conventional heating system leads to a positive net present value over a certain accepted period of time. With regulation in place on electricity feed-back tariffs and with a possible government investment subsidy the net present value of the extra investment might turn out to be positive over a period of about 5 years [7]. Then the investment in $\mu \mathrm{CHP}$ will provide considerable cost savings considering a lifetime of the system of some 15-20 years. This is shown by the move downwards in the household costs in Fig. 2. Due to the decrease in primary energy consumption of a household with $\mu \mathrm{CHP}$ (more gas use, but less electricity imports) the net revenues from $\mu \mathrm{CHP}$ customers will probably decrease for suppliers. This is even more so if suppliers will pay households for electricity that is fed back into the system. Since the supplier presently makes profit on electricity sold, he has no direct incentive to reduce the number of $\mathrm{kWhs}$ sold. The supplier could, however, invest in $\mu$ CHP himself and then lease $\mu$ CHPs to households. In that way he also captures customers in a competitive retail market. Also, new incentive structures, enforced by regulation, might provide suppliers with profits that are not solely dependent on the amount of energy sold. This is represented by the dashed piece-wise constant decreasing line representing aggregator costs in Fig. 2.

The third system of Fig. 2 might lead to more cost advantages for households and aggregator due to the application of MPC in $\mu \mathrm{CHP}$ control. Households will only apply MPC if this leads to substantial cost savings. We note that an important requirement for the potential cost savings with MPC is the presence of more real-time electricity pricing for household customers: with a flat rate, anticipative behavior aimed at cost reductions is useless. Contracts incorporating more real-time electricity import and/or export tariffs for residential customers could be offered by the supplier and we assume that these contracts are available. By providing the service of real-time tariffs to households, a household might be willing to share in the cost savings that MPC could entail for him. Sharing in the cost benefits could be contractually arranged between the supplier and the household. Also, when the application of $\mu \mathrm{CHP}$, with or without MPC, leads to peak load reduction, the supplier might possibly have to buy less expensive peak electricity for its customers. Cost savings due 




Figure 2: Four possible configurations of residential systems (top) and the accompanying costs for household and supplier (bottom).

to this could then be shared with households (e.g., via lower electricity or gas tariffs). Possible peak load reductions could also make network operators willing to reward households for applying (MPCcontrolled) $\mu \mathrm{CHPs}$. These rewards could then flow to households via their supplier. Because a government might want to stimulate $\mu \mathrm{CHP}$ penetration in society, it could support the technology by providing subsidies to suppliers promoting $\mu \mathrm{CHP}$ to their customers or by making it obligatory for suppliers to provide the service of real-time electricity pricing to households.

In the fourth system, the addition of a battery for electricity storage is expected to lead to more flexible control and therefore to more cost reduction potential for households with MPC. Costs for the supplier may further decrease by leasing batteries to households.

In the remaining part of the paper we will quantify the potential cost benefits of the systems described above.

\section{System Model Formulation}

\subsection{Mathematical system model formu- lation}

Here the mathematical model of the system of Fig. 1 is described. First we define the binary variables $v_{k}^{\mathrm{CHP}}$ and $v_{k}^{\text {aux }}$, which indicate whether the installed $\mu \mathrm{CHP}$ prime mover and auxiliary burner are in operation at a specific time step $k$. In addition, the binary variables $u_{\mathrm{up}, k}^{\mathrm{CHP}}, u_{\mathrm{down}, k}^{\mathrm{CHP}}$ and $u_{\mathrm{up}, k}^{\mathrm{aux}}, u_{\mathrm{down}, k}^{\text {aux }}$ are startup and shut-down indicators for the $\mu$ CHP prime mover and auxiliary burner, respectively, at time step $k$.

An electric energy balance has to be satisfied re- lating the power output of the Stirling engine, the input and output power flows of the electricity storage, the electricity consumption, and electricity exchanged with the energy supplier. This power balance is given by:

$$
g_{k}+i_{\mathrm{ext}, k}+s_{\mathrm{O}, k}-e_{\mathrm{ext}, k}-s_{\mathrm{i}, k}-e_{\mathrm{c}, k}=0,
$$

where $g_{k}=\eta_{\mathrm{e}} \cdot f_{1, k}$, with $\eta_{\mathrm{e}}$ the electric efficiency of the Stirling engine. The power output of the Stirling engine can be modulated between part load and full load, which is modeled by the constraints:

$$
\begin{aligned}
& f_{1, k} \leq v_{k}^{\mathrm{CHP}} \cdot f_{1, \text { max }} \\
& f_{1, k} \geq v_{k}^{\mathrm{CHP}} \cdot f_{1, \text { part }},
\end{aligned}
$$

where $f_{1, \max }$ and $f_{1, \text { part }}$ are the fuel consumption at part and full load. For the Stirling engine there is also a minimal operation time and a minimum down time. The constraints that force the prime mover to stay in operation until this minimum has been reached are:

$$
v_{k+n}^{\mathrm{CHP}} \geq u_{\mathrm{up}, k}^{\mathrm{CHP}}, \quad n=0, \ldots, t_{\mathrm{up}}-1,
$$

where $t_{\text {up }}$ is the minimum number of simulation time steps that the prime mover has to stay in operation. The constraints that force the prime mover to stay out of operation during down-time are:

$$
1-v_{k+r}^{\mathrm{CHP}} \geq u_{\mathrm{down}, k}^{\mathrm{CHP}}, \quad r=0, \ldots, t_{\mathrm{down}}-1,
$$

where $t_{\text {down }}$ is the minimum number of simulation time steps that the prime mover has to stay out of operation.

The fuel consumption of the auxiliary burner is restricted to lie within:

$$
v_{k}^{\text {aux }} \cdot f_{2, \min } \leq f_{2, k} \leq v_{k}^{\text {aux }} \cdot f_{2, \max },
$$

where $f_{2, \min }$ and $f_{2, \max }$ are the minimal and maximum fuel consumption of the auxiliary burner.

The electrical energy and heat stored should be between minimum and maximum values:

$$
\begin{aligned}
& e_{\mathrm{s}, \min } \leq e_{\mathrm{s}, k} \leq e_{\mathrm{s}, \max } \\
& h_{\mathrm{s}, \min } \leq h_{\mathrm{s}, k} \leq h_{\mathrm{s}, \max }
\end{aligned}
$$

where $e_{\mathrm{s}, \min }$ and $e_{\mathrm{s}, \max }$ are minimum and maximum energy levels of the battery, and $h_{\mathrm{s}, \min }$ and $h_{\mathrm{s}, \max }$ are minimum and maximum energy levels of the heat storage.

The electricity flows to and from the battery are limited by an assumed battery charge or discharge time of half an hour [8]. This means that within one simulation time step of 15 minutes, the battery could 
be maximally charged or discharged with an amount equal to half the total storage capacity. Because the battery could be charged as well as discharged in one simulation time step, the constraint limiting the flows to and from the battery is given by:

$$
s_{\mathrm{i}, k}+s_{\mathrm{o}, k} \leq 0.5 \cdot e_{\mathrm{s}, \max },
$$

where $e_{\mathrm{s}, \max }$ is the maximum energy that can be stored in the battery. At each time step $k$ electrical energy can either only be imported from or only be exported to the external energy supplier. Constraints on the import and export power flows are therefore:

$$
\begin{aligned}
& e_{\mathrm{ext}, k} \leq \eta_{\mathrm{e}} \cdot f_{1, k}+s_{\mathrm{o}, k} \\
& e_{\mathrm{ext}, k} \leq x_{\mathrm{e}, k} \cdot P_{\max } \\
& i_{\mathrm{ext}, k} \leq e_{\mathrm{c}, k}+s_{\mathrm{i}, k} \\
& i_{\mathrm{ext}, k} \leq x_{\mathrm{i}, k} \cdot P_{\max } \\
& x_{\mathrm{i}, k}+x_{\mathrm{e}, k} \leq 1,
\end{aligned}
$$

where $P_{\max }$ is the maximum power flow allowed through the physical connection between the household and the external network and $x_{\mathrm{e}, k}$ and $x_{\mathrm{i} k}$ are auxiliary binary variables indicating whether electrical energy is imported or exported

The heat in the heat storage changes over time depending on the heat consumption and generation. The dynamics of the heat storage are modeled by:

$$
h_{\mathrm{s}, k+1}=h_{\mathrm{s}, k}+h_{1, k}+h_{2, k}-h_{\mathrm{cp}, k},
$$

where $h_{1, k}=\left(\eta_{\text {tot }}-\eta_{\mathrm{e}}\right) \cdot f_{1, k}, h_{2, k}=\eta_{\text {tot }} \cdot f_{2, k}$, and $\eta_{\text {tot }}$ is the total efficiency of the $\mu$ CHP unit. Similarly, the dynamics of the electricity storage are modeled by:

$$
e_{\mathrm{S}, k+1}=e_{\mathrm{s}, k}+s_{\mathrm{i}, k}-s_{\mathrm{O}, k}
$$

In order to let the modeled energy conversion units function as they should, the binary variables $v_{k}^{\mathrm{CHP}}, u_{\mathrm{up}, k}^{\mathrm{CHP}}$, and $u_{\mathrm{down}, k}^{\mathrm{CHP}}$ on the one hand, and $v_{k}^{\text {aux }}$, $u_{\mathrm{up}, k}^{\text {aux }}$, and $u_{\text {down }, k}^{\text {aux }}$ on the other, have to be linked. The relations between these variables are:

$$
\begin{aligned}
& v_{k}^{\mathrm{CHP}}-v_{k-1}^{\mathrm{CHP}}=u_{\mathrm{up}, k}^{\mathrm{CHP}}-u_{\mathrm{down}, k}^{\mathrm{CHP}} \\
& v_{k}^{\mathrm{aux}}-v_{k-1}^{\mathrm{aux}}=u_{\mathrm{up}, k}^{\mathrm{aux}}-u_{\mathrm{down}, k}^{\mathrm{aux}} \\
& u_{\mathrm{up}, k}^{\mathrm{CHP}}+u_{\mathrm{down}, k}^{\mathrm{CHP}} \leq 1 \\
& u_{\mathrm{up}, k}^{\mathrm{aux}}+u_{\mathrm{down}, k}^{\mathrm{aux}} \leq 1 .
\end{aligned}
$$

The first system of Fig. 2 with conventional heating is described by the equations (1), with only the electricity consumption and import flows, (6), (8), (15), (18) and (20). The model of the third system is identical to the model of the fourth system, except for that the equations regarding the battery are omitted.

Stringent, heat-led, control is envisaged to be a standard control strategy to be used for $\mu \mathrm{CHPs}$ when they enter the market. The heuristics underlying this control mode are described in detail in [7]. We briefly explain how the heat-led control was modeled. The water in the central heat storage is heated by the Stirling engine from a minimum temperature of $T_{\mathrm{s}, \text { min_CHP }}$ up to a maximum of $T_{\mathrm{s}, \text { max }} \mathrm{CHP}$ and should then stop operating again until $\mathrm{T}_{\mathrm{s}, \text { min_CHP }_{\mathrm{C}}}$ is reached again. If the temperature drops below a certain level, $T_{\mathrm{s}, \min \_a u x}$, the auxiliary burner heats the water from this $T_{\mathrm{s} \text {,min_aux }}$ to $T_{\mathrm{s} \text {,max_aux }}$. The values of the temperature levels were set as shown in Fig. 3 after consulting boiler manufacturers. The Stirling engine can operate at full load capacity in our model. So the only criterion on which the $\mu \mathrm{CHP}$ is operated is temperature. Interested readers are advised to consult [7] for more details.

\subsection{MPC control objective}

The objective of the MPC controller is to minimize the daily operational costs of residential energy use. These costs depend on the price $p_{\mathrm{f}}$ for gas consumption, the hourly-varying import electricity price $p_{\mathrm{i}, \mathrm{ext}}$ and the (possibly time-varying) price at which electricity can be sold, $p_{\mathrm{e}, \mathrm{ext}}$. The cost function for control step $k$ with a prediction horizon of $N$ is therefore defined as

$$
\begin{aligned}
J(\cdot)= & \sum_{m=0}^{N-1}\left(\left(f_{1, k+m}+f_{2, k+m}\right) \cdot p_{\mathrm{f}}\right. \\
& \left.+i_{\mathrm{ext}, k+m} \cdot p_{\mathrm{i}, \mathrm{ext}, k+m}-e_{\mathrm{ext}, k+m} \cdot p_{\mathrm{e}, \mathrm{ext}}\right) .
\end{aligned}
$$

At each time step $k$ the controller first measures or estimates the current state of the system. Then, it formulates its MPC problem over a prediction horizon of $N$ prediction steps, where the length of one prediction step is defined as 15 minutes. The resulting optimization problem involves minimizing (21) subject to the equality and inequality constraints (1)-(20) (or a selection thereof, depending on the system studied) over the prediction horizon $N$. Due to the occurrence of both continuous-valued variables and binary-valued variables in combination with a linear objective function and linear equality and inequality constraints, this optimization problem is a mixed-integer linear programming problem. 


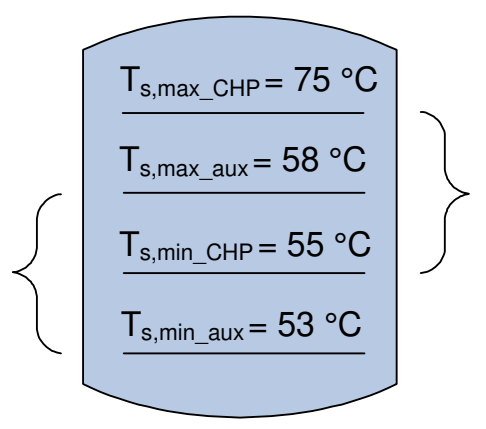

Figure 3: Temperature levels of the water in the heat storage with which the thermal-led control operates.

\section{Simulation Results}

\subsection{Simulation input}

Residential electricity and aggregated heat demand profiles have been created with 2006 data from 'EnergieNed', the Dutch Federation of Energy Companies. The profiles represent the consumption for an average Dutch household. Heat profiles have a resolution of one hour and electricity profiles of $15 \mathrm{~min}$ utes. We used a gas price of $0.06 € / \mathrm{kWh}$ [9]. The hourly varying electricity price has been constructed by substituting the variable supply part of the residential electricity tariff $(0.06 € / \mathrm{kWh}$ on a total variable tariff of about $0.17 € / \mathrm{kWh}$ [10]) with Dutch power exchange prices of 2006. Because power exchange prices are known a day in advance these can be conveyed to the household and used in the MPC strategy. We have assumed the predicted residential heat and electricity demand which the MPC controller uses as being equal to the actual demand. In calculating the heat storage content we have used a storage volume of 100 liters and an environmental temperature of $20^{\circ} \mathrm{C}$. In the MPC model minimum and maximum temperatures for the heat storage of $55^{\circ} \mathrm{C}$ and $80^{\circ} \mathrm{C}$ were set, respectively. The battery has a storage capacity of $2 \mathrm{kWh}$.

\subsection{Results}

We have implemented the systems and MPC controllers in Matlab v7.3 [11] using ILOG CPLEX v10 through the Tomlab interface to Matlab [12]. Various other publicly and commercially available solvers (such as, e.g., miqp, LP_Solve, and MIQPbb) for mixed-integer optimization problems were not able to solve the complex mixed-integer optimization problems at hand. With a prediction horizon of, e.g., 96 steps, at each simulation time step an op- timization problem consisting of around 2000 equations and 1000 variables (continuous and binary) has to be solved.

We have simulated system behavior for a three month winter period with prediction lengths $N$ for the MPC controller varying between 1 and 96 time steps. The simulation results are shown in Fig. 4 and 5. Fig. 5 differs from Fig. 4 in that simulations were done with an electricity export price of 0. In Fig. 4 the feed-back tariff for households was equal to the variable import tariff.

Looking at the results of Fig. 4 and 5 and comparing them with our hypotheses of Section III, the following insights are gained. The conventional system leads to energy costs of around $540 €$ in the 3 month period. A household with a heat-led $\mu \mathrm{CHP}$ will have costs of around $490 €$ when there is no feed-back tariff and $382 €$ with the variable tariff. This shows the savings for $\mu \mathrm{CHP}$ households and the necessity for a feed-back tariff to make $\mu \mathrm{CHP}$ really financially attractive to households. The savings that can be achieved without a feed back tariff are too little to lead to acceptable returns on investment and therefore will not convince consumers with average annual heat and electricity demand to invest in Stirling $\mu \mathrm{CHP}$.

With the more flexible MPC control applied to $\mu \mathrm{CHP}$ cost savings can be achieved when compared to the heat-led system if a sufficiently long prediction horizon is used by the controller. Substantial cost savings can be achieved when there is no electricity feed-back tariff. For $N=1$ savings are then around $53 €$ and around $64 €$ for $N=96$. When a variable feed-back tariff is present, MPC does not lead to significant savings (around $6 €$, for $N=96$ when compared to the heat-led system) and will probably not outweigh the investments in the MPC controller and additional ICT.

Adding the battery storage of $2 \mathrm{kWh}$ capacity to an MPC controlled system leads to additional savings of about $30 €$ in 3 months (with feed-back tariff present). These savings are exactly equal when adding the battery either to the conventional system or to the $\mu \mathrm{CHP}$ system. When there is no feed-back tariff these savings are only around $17 €$. With present investment costs of residential batteries of around 500-1000 $€ / \mathrm{kWh}$ [8] these savings will not outweigh the investments in a stand-alone battery. With possible pluggable hybrid vehicles in the future, however, using these vehicles as MPCcontrolled electricity storage systems at times when the user does not drive the car, seems a very interesting option. 


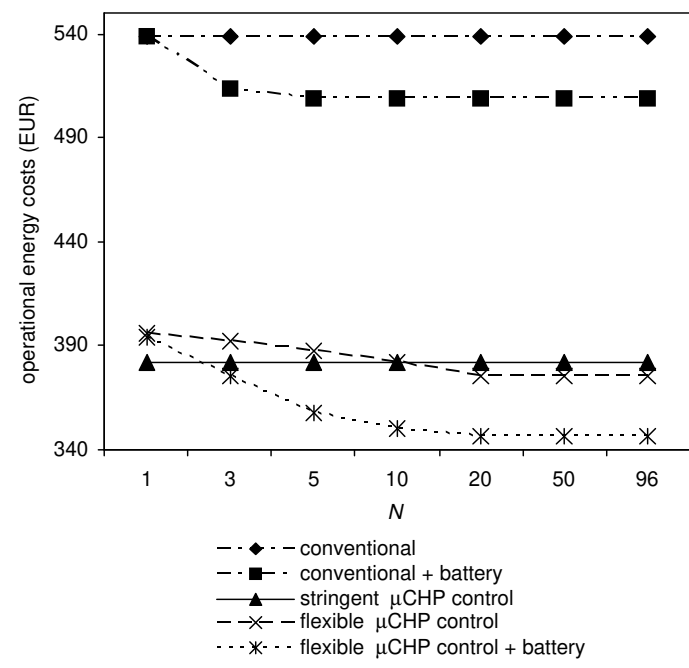

Figure 4: Full simulation costs, for varying N, and for different systems, with equal electricity import and export tariffs.

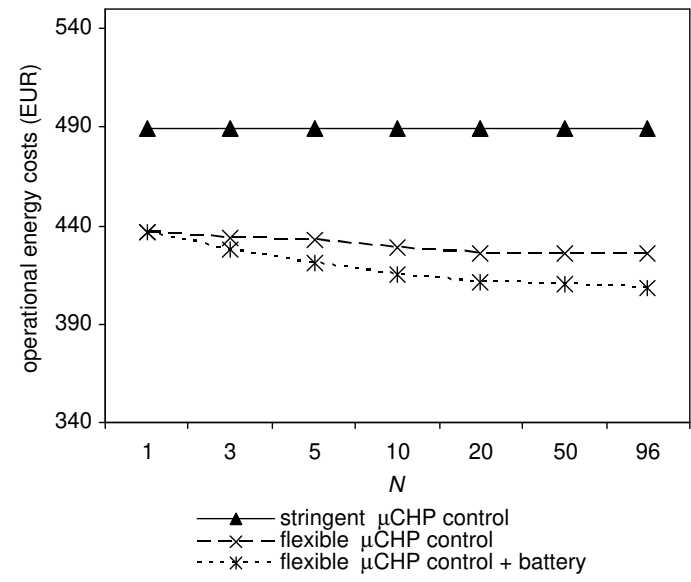

Figure 5: Full simulation costs, for varying N, and for different systems, with no export tariff.

\section{Conclusions and Further Study}

We have discussed the application of model predictive control (MPC) to various, increasingly complex configurations of households. Simulation results illustrated that MPC gives better outcomes in terms of daily energy costs when a larger prediction horizon is adopted by the controller. We also illustrated that applying MPC to $\mu \mathrm{CHP}$ does not lead to substantial energy cost savings in the case where the electricity feed-back tariff is equal to the import tariff. However, with a zero feed-back tariff, MPC control of $\mu \mathrm{CHP}$ is financially very attractive.
We thus showed that MPC control of distributed energy resources (DERs) can lead to cost savings, but that these savings are strongly dependent on the controlled physical systems and their surroundings in terms of (regulated) energy tariffs. We see MPC as a means of making DERs more cost effective due to the possibility of decreasing variable costs, but recommend MPC controllers to be designed in such a way that they are flexible and can adjust to evolving systems and system environments.

Interesting options for further research are to apply MPC to fuel cell $\mu$ CHP systems, due to the inherent different characteristics of fuel cells as compared to Stirling engines (e.g., the much smaller heat-to-power ratio for the fuel cell). Also larger heat storage capacities might improve the benefits of MPC control of $\mu \mathrm{CHP}$, due to the increased flexibility in control. Further, virtual power plants, in which clusters of $\mu \mathrm{CHP}$ households could be centrally controlled using an MPC approach, might also lead to lower energy costs for a cluster of households and could further lead to better economies of scale in terms of information and communication technology investments.

\section{References}

[1] N. Hatziargyriou, H. Asano, R. Iravani, and C. Marnay, "Microgrids: An Overview of Ongoing Research, Development, and Demonstration Projects," IEEE Power \& Energy Magazine, pp. 7894, July/August 2007.

[2] N. Jenkins, R. Allan, P. Crossley, D. Kirschen, and G. Strbac, Embedded Generation, Padstow, UK: TJ International, 2000.

[3] M. Pehnt, M. Cames, C. Fischer, B. Praetorius, L. Schneider, K. Schumacher, and J. Vob, Micro Cogeneration: Towards Decentralized Energy Systems. Berlin: Springer, 2006.

[4] A. De Jong, E. J. Bakker, J. Dam, and H. Van Wolferen, "Technisch energie- en CO2besparingspotentieel van micro-wkk in Nederland (2010-2030)," Werkgroep Decentraal, onderdeel van Platform Nieuw Gas, July 2006. In Dutch.

[5] M. Houwing, R. R. Negenborn, P. W. Heijnen, B. De Schutter, and J. Hellendoorn, "Model predictive, least cost control of residential energy resources when applying $\mu$ CHP," in Proc. of PowerTech 2007, Lausanne, Switzerland, July 2007.

[6] J. M. Maciejowski, Predictive Control with Constraints. Harlow, England: Prentice Hall, 2002.

[7] M. Houwing and I. Bouwmans, "Agent-Based Modeling of Residential Energy Generation with MicroCHP," in Proc. of the 2nd International Conference 
on Integration of Renewable and Distributed Energy Resources, Napa, CA, USA, December 2006.

[8] E. Lysen, S. Van Egmond, and S. Hagedoorn, “Opslag van elektriciteit: Status en toekomstperspectief voor Nederland," Utrecht Centrum voor Energieonderzoek - SenterNovem NEO 0268-05-05-01-002, September 2006. In Dutch.

[9] http://www.cbs.nl/, "Dutch Central Bureau of Statistics (CBS)," 2008.

[10] http://www.energie.nl/, "Official informative website of the Energy research Centre of the Netherlands (ECN)," 2008.

[11] http://www.mathworks.com/, "Mathworks, Matlab," 2008.

[12] K. Holström, A. O. Göran, and M. M. Edvall, "User's guide for Tomlab /CPLEX," June 2007. 